\title{
GAMBARAN KECEMASAN DENGAN PERUBAHAN TEKANAN DARAH DAN DENYUT NADI PADA PASIEN EKSTRAKSI GIGI DI RSUD BARRU
}

\author{
Hans Lesmana, Agus Supriatna
}

\begin{abstract}
ABSTRAK
Rasa cemas merupakan salah satu tipe gangguan emosi yang berhubungan dengan situsai tak terduga atau dianggap berbahaya. Adapun tanda-tanda fisiologis yang menyertainya yaitu, keringat, tekanan darah meningkat, denyut nadi bertambah, berdebar, mulut kering, dan ketengangan otot. Tujuan penelitian ini yaitu, mengetahui gambaran kecemasan dengan perubahan tekanan darah dan denyut nadi pada pasien ekstraksi gigi diRSUD barru. Penelitian ini merupakan penelitian deskriptif dengan pendekatan cross-sectional study yang dilakukan diRSUD Barru. Populasi dan sampel adalah seluruh pasien yang berkunjung diRSUD barru yang ingin melakukan tindakan ekstraksi gigi. Teknik pengambilan sampel menggunakan total sampling. Data diambil dengan melakukan pengukuran tekanan darah dan denyut nadi yang dilakukan saat menunggu diruang tunggu, saat berada dikursi dental sebelum ekstraksi gigi, dan setelah ekstraksi gigi. Hasil penelitian dari 31 sampel yang didapat sebanyak 16 orang $(51,6 \%)$ yang mengalami peningkatan tekanan darah dan denyut nadi sebelum dan sesudah ektraksi gigi. Usia 25-34 tahun merupakan usia terbanyak mengalami kecemasan serta berjenis kelamin perempuan yang paling banyak mengalami cemas.
\end{abstract}

Kata Kunci : Kecemasan, Tekanan darah, Denyut nadi, Ekstraksi gigi

\section{PENDAHULUAN}

Kesehatan gigi dan mulut merupakan bagian integral dari kesehatan manusia seutuhnya, dengan demikian upaya dalam bidang kesehatan gigi pada akhirnya akan turut berperan dalam peningkatan kualitas dan produktivitas sumber daya manusia. Kebersihan gigi dan mulut merupakan hal yang sangat penting dalam mencegah terjadinya penyakit-penyakit dirongga mulut. (Wijaya, 2015).

Pada umumnya masyarakat memberi kesan bahwa praktek dokter gigi memiliki suasana dan peralatan yang asing, dan terlebih lagi berhubungan dengan rasa nyeri. $\mathrm{Hal}$ ini menyebabkan pasien menjadi cemas sehingga mempengaruhi kunjungan rutin pasien untuk berobat ke dokter gigi. ( Tamunu, Wantania, Mariati, 2015). Di seluruh dunia prevalansi kecemasan pada perawatan gigi sangat tinggi yaitu mencapai $6-15 \%$ dari seluruh populasi. Namun cukup bervariasi di berbagai dunia dan pada pada populasi sampel yang berbeda. (Rehatta, 2014).

Menurut penelitian yang dilakukan oleh Cormac dan Jenkins yang diukur dengan tiga jenis kuesioner yang berbeda pada populasi yang sama menunjukkan bahwa prevalensi rasa takut terhadap perawatan gigi berkisar 8,2-24\%. (Kandou, Gunawan , Lolong ,2014). Penelitian yang dilakukan oleh Wardle menunjukkan bahwa tindakan ekstraksi gigi merupakan pencetus pertama kecemasan seseorang. Kecemasan pada tindakan ekstraksi gigi sering disebabkan oleh penggunaan benda-benda tajam seperti jarum, elevator (bein) dan tang, yang dimasukkan secara berurutan maupun bergantian dalam mulut.Selain itu kecemasan pasien biasanya berasal dari ketakutan terhadap rasa sakit. Adapun kecemasan dikarenakan mereka ragu terhadap apa yang akan mereka alami dan ada juga yang bersifat menurun dalam keluarga. ( Pontoh, Pangemanan, Mariati, 2015).

Berdasarkan laporan hasil Riset Kesehatan Dasar (RISKESDAS) Nasional tahun 2013, dari hasil wawancara sebesar $25,9 \%$ penduduk Indonesia mempunyai masalah gigi dan mulut dalam 12 bulan terakhir (potential demand). Di antara mereka, terdapat $31,1 \%$ yang menerima perawatan dan pengobatan dari tenaga medis gigi (perawat gigi, dokter gigi atau dokter gigi spesialis), 
sementara 68,9\% lainnya tidak dilakukan perawatan. ( Pontoh, Pangemanan, Mariati, 2015).

Rasa cemas merupakan salah satu tipe gangguan emosi yang berhubungan dengan situasi tak terduga atau dianggap berbahaya. Adapun tanda-tanda fisiologis yang menyertainya yaitu, berkeringat, tekanan darah meningkat, denyut nadi bertambah, berdebar, mulut kering, diare, ketegangan otot dan hiperventilasi.Kecemasan preoperative memiliki sifat subyektif, dan secara sadar perasaan tentang kecemasan serta ketegangan yang disertai perangsangan sistem saraf otonom menyebabkan peningkatan tekanan darah, denyut jantung dan tingkat respirasi. Hal ini sangat berbahaya karena tingginya denyut jantung dan tekanan darah akan memperberat kerja sistem kardiovaskuler dan meningkatkan kebutuhan oksigen dan kerja jantung. Selain itu, kecemasan yang dialami oleh pasien akan semakin meningkat apabila adanya persepsi dari pasien, yaitu keterampilan atau keahlian dokter gigi yang akan melakukan prosedur pencabutan gigi tersebut masih cukup kurang. ( Permatasari, 2013)

Denyut nadi distimulasi oleh serabut saraf simpatis dan penurunan frekuensi denyut nadi distimulasi oleh serabut parasimpatis. Denyut nadi merupak sistem kerja jantung, sehingga pada keadaan jantung berdebar- debar yang dikemukakan para ahli psikologis merupakan salah sebuah gejala fisik kecemasan tingkat fisiologis.(Pontoh, Pangemanan, Mariati, 2015).

\section{METODE PENELITIAN}

Jenis penelitian yang digunakan adalah Deskriptif yaitu hanya menggambarkan hasil penelitian. Penelitian ini dilaksanakan di RSUD Barru. Penelitian ini dilaksanakan pada bulan AprilMei 2017. Populasi penelitian adalah pasien RSUD Barru, sampel penelitian adalah pasien yang akan melakukan ekstraksi gigi yang diambil secara Total Sampling.

Subjek didudukan ditempat yang disediakan, penyampaian tujuan dan pengarahan penelitian, Subjek melakukan pengisian informed consent. Subjek dilakukan pengukuran tekanan darah dan denyut nadi sebelum dan setelah ekstraksi gigi.

\section{HASIL DAN PEMBAHASAN}

\section{Hasil Penelitian}

Berdasarkan penelitian yang dilaksanakan di RSUD Barru dengan menggunakan teknik pengambilan sampel secara total sampling yaitu dimana peneliti pengambil sampel secara keseluruhan. Dari hasil penelitian tersebut maka didapatkan yang diolah pada tabel distribusi sebagai berikut.

Tabel 1. Distribusi Frekuensi Kecemasan Berdasarkan Jenis Kelamin

\begin{tabular}{|c|c|c|r|r|}
\hline \multirow{2}{*}{ Tingkat kecemasan } & \multicolumn{2}{|c|}{ Laki-laki } & \multicolumn{2}{c|}{ Perempuan } \\
\cline { 2 - 5 } & $\mathrm{n}$ & \multicolumn{1}{|c}{$\%$} & \multicolumn{1}{c|}{$\mathrm{n}$} & \multicolumn{1}{c|}{$\%$} \\
\hline Cemas & 3 & $9,6 \%$ & 13 & $41,9 \%$ \\
\hline Tidak cemas & 12 & $38,7 \%$ & 3 & $9,6 \%$ \\
\hline Total & 15 & $48,3 \%$ & 16 & $51.5 \%$ \\
\hline
\end{tabular}


Berdasarkan tabel 1. menunjukan bahwa dari 31 pasien ekstraksi gigi di RSUD Barru terdapat 3 orang $(9,6 \%)$ laki-laki yang mangalami kecemasan dan 12 orang (38,7\%) laki-laki yang tidak cemas. 3 orang $(9,6 \%)$ perempuan yang tidak mengalami kecemasan dan 13 orang (41,9\%) perempuan yang mengalami kecemasan.

Tabel 2. Distribusi Frekuensi Kecemasan Berdasarkan Usia

\begin{tabular}{|c|c|c|c|c|}
\hline \multicolumn{5}{|c|}{ Tingkat Kecemasan } \\
\hline \multirow{2}{*}{ Usia (Tahun) } & \multicolumn{2}{|c|}{ Tidak cemas } & \multicolumn{2}{c|}{ Cemas } \\
\cline { 2 - 5 } & $\mathrm{N}$ & $\%$ & $\mathrm{~N}$ & $\%$ \\
\hline $17-20$ & 5 & $16,1 \%$ & 1 & $3,2 \%$ \\
\hline $21-30$ & 3 & $9,6 \%$ & 8 & $25,8 \%$ \\
\hline $31-40$ & 4 & $12,9 \%$ & 5 & $16,1 \%$ \\
\hline $41-50$ & 1 & $3,2 \%$ & 2 & $6,4 \%$ \\
\hline $51-60$ & 0 & 0 & 0 & 0 \\
\hline $61-70$ & 1 & $3,2 \%$ & 0 & 0 \\
\hline $71-80$ & 1 & $3,2 \%$ & 0 & 0 \\
\hline Total & 15 & $48,2 \%$ & 16 & $51.5 \%$ \\
\hline
\end{tabular}

Berdasarkan Tabel 2. di atas menunjukan bahwa dari 31 pasien ekstraksi gigi di RSUD Barru berdasarkan usianya yaitu sebanyak 5 orang $(16,1$ $\%)$ tidak cemas dan 1 orang (3,2\%) yang cemas pada usia $17-20$. 3 orang $(9,6 \%)$ yang tidak cemas dan 8 orang $(25,8 \%)$ yang cemas pada usia 21-30.
4 orang $(12,9 \%)$ yang tidak cemas dan 5 orang $(16,1 \%)$ yang cemas pada usia 31-40. $1(3,2 \%)$ yang tidak cemas dan 2 orang $(6,4 \%)$ yang cemas pada usia $41-50.1$ orang $(3,2 \%)$ yang tidak cemas pada usia 61-70. Dan 1 orang $(3,2 \%)$ yang tidak cemas pada usia 71-80.

Tabel 3. Distribusi Frekuensi Perubahan Tekanan Darah Sebelum Ekstraksi Gigi

\begin{tabular}{|c|c|c|}
\hline Perubahan Tekanan darah & $\mathrm{N}$ & $\%$ \\
\hline Tetap & 15 & $48,3 \%$ \\
\hline Meningkat & 16 & $51,6 \%$ \\
\hline Menurun & 0 & 0 \\
\hline Total & 31 & $100 \%$ \\
\hline
\end{tabular}

Tabel 3. menunjukan bahwa dari 31 pasien ekstraksi gigi di RSUD Barru sebanyak 15 orang
$(48,3 \%)$ tekanan darahnya tetap,dan sebanyak 16 orang $(51,6 \%)$ tekanan darahnya naik. 
Tabel 4. Distribusi Frekuensi Perubahan Tekanan Darah Setelah Ekstraksi Gigi

\begin{tabular}{|c|c|c|}
\hline Perubahan Tekanan darah & $\mathrm{N}$ & $\%$ \\
\hline Tetap & 14 & $45,1 \%$ \\
\hline Meningkat & 16 & $51,6 \%$ \\
\hline Menurun & 1 & $3,2 \%$ \\
\hline Total & 31 & $100 \%$ \\
\hline
\end{tabular}

Berdasarkan tabel 4. di atas menunjukkan bahwa dari 31 pasien ekstraksi gigi di RSUD Barru sebanyak 14 orang $(45,1 \%)$ yang tekanan darahnya tetap. 16 orang $(51,6 \%)$ tekanan darahnya meningkat dan 1 orang $(3,2 \%)$ yang tekanan darahnya menurun.

Tabel 5. Distribusi Frekuensi Perubahan Denyut Nadi Sebelum Ekstraksi Gigi

\begin{tabular}{|c|c|c|}
\hline Perubahan Denyut Nadi & N & $\%$ \\
\hline Tetap & 15 & $48,3 \%$ \\
\hline Meningkat & 16 & $51,6 \%$ \\
\hline Menurun & 0 & 0 \\
\hline Total & 31 & $100 \%$ \\
\hline
\end{tabular}

Berdasarkan tabel 3.diatas menunjukan bahwa dari 31 pasien ekstraksi gigi di RSUD Barru sebanyak 15 orang $(48,3 \%)$ denyut nadinya tetap,dan sebanyak 16 orang $(51,6 \%)$ denyut nadinya meningkat.

Tabel 6. Distribusi Frekuensi Perubahan Denyut Nadi Setelah Ekstraksi Gigi

\begin{tabular}{|c|c|c|}
\hline Perubahan Denyut Nadi & $\mathrm{N}$ & $\%$ \\
\hline Tetap & 14 & $45,1 \%$ \\
\hline Meningkat & 16 & $51,6 \%$ \\
\hline Menurun & 1 & $3,2 \%$ \\
\hline Total & 31 & $100 \%$ \\
\hline
\end{tabular}


Berdasarkan tabel 6. di atas menunjukkan bahwa dari 31 pasien ekstraksi gigi di RSUD Barru sebanyak 14 orang (45,1\%) yang denyut nadinya tetap. 16 orang $(51,6 \%)$ denyut nadinya meningkat dan 1 orang (3,2\%) yang denyut nadinya menurun.

\section{Pembahasan}

Tekanan darah adalah kekuatan yang diperlukan agar darah dapat mengalir di dalam pembuluh darah dan beredar mencapai seluruh jaringan. Tekanan darah tergantung pada kekuatan dan volume darah yang dipompa oleh jantung serta kontrakdir otot arterior. Tekanan darah berbeda pada tiap pembuluh darah vena, tertinggi pada arteri besar yang berdekatan dengan jantung dan menurun secara bertahap pada arteri yang lebih kecil ,arteriol, dan kapiler. Secara umum ada dua komponen tekanan darah, yaitu tekanan sistoik merupakan tekanan pada dinding pembuluh darah setelah sistolik ventrikuler,ketika arteri mengandung banyak darah,maka saat itu terjadi tekanan yang maksimal. Tekanan sistolik ditentukan oleh jumlah darah yang diejeksikan kedalam arteri (isi sekuncup),kekuatan kontraksi. Tekanan diastolik merupakan tekanan pada dinding pembuluh darah diastole ventrikuler,ketika arteri hanya berisi sedikit darah, tekanan pada dinding pembuluh darah juga berkurang. Tekanan diastole ini dipengaruhi oleh tekanan sistolik dan curah jantung. Pengaruh stress dan cemas terkait dengan peningkatan tekanan darah ( Johnson, Taylor 2004).

Denyut nadi distimulasi oleh serabut saraf simpatis dan penurunan frekuensi denyut nadi distimulasi oleh serabut parasimpatis. Denyut nadi merupakan bagian dari sistem kerja jantung, sehingga pada keadaan jantung yang berdebardebar dalam teori yang dikemukakan oleh para ahli psikologis merupakan salah satu wujud gejala fisik pada kecemasan tingkat fisiologis. Nadi teraba diseluruh bagian tubuh dimana arteri dapat dipalpasi diatas bagian keras,biasanya tulang.
Nadi yang lemah atau kuat,cepat atau penuh semuanya mengindikasikan perubahan dalam jumlah darah yang dipompakan (Pontoh dkk, 2015).

Keadaan cemas pada ekstraksi gigi dialami oleh siapa saja.Hasil distribusi frekuensi kecemasan berdasarkan jenis kelamin menunjukan bahwa perempuan lebih banyak mengalami kecemasan untuk melakukan ekstraksi gigi. Dari 31 pasien ekstraksi gigi,laki-laki yang mengalami kecemasan sebanyak 3 orang $(9,6 \%)$ dan perempuan sebanyak 13 orang (41,9\%). Penelitian ini sesuai dengan penelitian yang dilakukan oleh Jacklin di Santo Olaf College yang terletak di Carolina Utara (2004) yang mengatakan perempuan lebih cemas dari pada laki-laki. Pada penelitian ini,dinyatakan bahwa perempuan cenderung lebih sensitif dibandingkan laki-laki yang memiliki jiwa pemberani. Hal ini disebabkan karena perempuan memiliki ambang toleransi sakit yang rendah dan secera umum wanita juga memiliki tingkat kecemasan yang tinggi. Perempuan juga lebih terbuka dalam mengekspresikan apa yang ada pada perasaannya dari pada pria yang cenderung lebih memendam apa yang sebenarnya dia rasakan dan memiliki emosi yang stabil (Rehatta $\mathrm{dkk}, 2014)$.

Penelitian hasil distribusi frekuensi kecemasan berdasarkan kelompok usia. Peneliti mendapatkan jumlah pasien yang mengalami kecemasan terbanyak pada usia 21-30 tahun sebanyak 8 orang ( $25,8 \%)$, diikuti pada kelompok usia 31-40 tahun sebanyak 5 orang (16,1\%),dan pada kelompok 41-50 tahun sebanyak 2 orang $(6,4 \%)$. Hasil penelitian ini hampir sama dengan hasil penelitian yang dilakukan oleh Pontoh yaitu menjelaskan bahwa tingkat kecemasan paling tinggi berada pada usia 25-34 tahun. Menurut peneliti ada banyak alasan pasien merasakan cemas,salah satunya adalah trauma dental masa lalu yang tidak dapat dilupakan oleh pasien. Pada Usia 25-34 kebanyakan orang mengalami stress atau cemas 
dikarena faktor hormon dan kebanyak pada usia 25-34 memiliki kesibukan yang sangat tinggi dan kebanyak pada usia tersebut sudah memiliki keluarga sehingga baik perempuan maupun lakilaki memiliki tingkat stress atau cemas yang tinggi.

Penelitian tingkat kecemasan dari hasil distribusi frekuensi kecemasan berdasarkan perubahan tekanan darah dan denyut nadi sebelum ekstraksi gigi,peneliti mendapatkan sebenyak 15 orang ( 48,3\%) tekanan darah dan denyut nadinya tetap, 16 orang ( $51,6 \%$ ) tekanan darah dan denyut nadinya meningkat dan tidak ada tekanan darah dan denyut nadi yang turun. Hal ini sangat berhubungan dengan tingkat kecemasan yang dialami pasien sebelum dan sesudah ekstraksi gigi dimana kecemasan,emosi,stres fisik,rasa takut dan sakit dapat meningkatkan tekanan darah,karena stimulasi sistem saraf simpatis yang meningkatkan curah jantung dan vasokonstriksi arterior,sehingga meningkatkan hasil tekanan darah. Pada keadaan stress atau cemas medulla kelenjar adrenal akan mengsekrisikan neropinefrin dan efinefrin,yang keduanya akan menyebebkan vasokonstriksi sehingga meningkatkan frekunsi jantung (denyut nadi). Apabila tekanan darah meningkat maka denyut nadi juga akan meningkat,karena tekanan darah meningkat sejalan dengan meningkatnya frekunsi jantung agar volume darah yang bersirkulasi tidak berubah.

Penelitian tingkat kecemasan dari hasil distribusi frekunsi kecemasan berdasarkan perubahan tekanan darah dan denyut nadi setelah ekstraksi gigi peneliti mendapatkan sebanyak 14 orang $(45,1 \%)$ tekanan darah dan denyut nadinya tetap, 16 orang $(51,6 \%)$ tekanan darah dan denyut nadinya meningkat dan 1 orang $(3,2 \%)$ yang mengalami penurunan tekanan darah dan denyut nadi. Penurunan ini biasanya dipengaruhi oleh faktor usia,dimana frekuensi jantung menurun sesuai dengan usia. Pada orang dewasa efek fisiologi usia dapat perpengaruh pada sistem kardiovaskuler. Penurunan tekanan darah dan denyut nadi ini biasanya dikarenakan adanya riwayat penyakit pasien,seperti pasien yang menderita hipotensi dan bradycardia. Penurunan tekanan darah dan denyut nadi dikerenakan curah jantung yang rendah dan volume darah yang rendah sehingga jantung tidak dapat memompa darah dengan cepat keseluruh tubuh.

Berdasarkan penelitian yang dilakukan, peneliti menyimpulkan bahwa terjadinya peningkatan tekanan darah dan denyut nadi dikarenakan adanya ketakutan dalam diri pasien yang melihat jarum suntik dan peralatan dokter gigi.

\section{SIMPULAN DAN SARAN}

\section{Simpulan}

Pasien yang tekanan darah dan denyut nadi naik sebanyak 16 orang $(51,6 \%)$, pasien yang tekanan darah dan denyut nadi tetap sebanyak 14 orang $(45,1 \%)$ dan 1 orang $(3,2 \%)$ yang mengalami penurunan tekanan darah dan denyut nadi.

\section{Saran}

Dokter gigi maupun perawat gigi perlu memahami bagaimana cara mengatasi kecemasan pasien dalam penanganannya, seorang dokter gigi maupun perawat gigi dapat menenangkan pasien dari rasa cemasnya. Usaha promosi tentang kesehatan gigi dan mulut kepada masyarakat perlu ditingkatkan agar masyarakat yang takut kedokter gigi tidak takut lagi dan mengenal tentang kesehatan gigi dan mulut.

\section{DAFTAR PUSTAKA}

1. Aprilia YI. 2014. Denyut Nadi.

2. Dewi AS. 2013. Exodontia Indikasi dan Kontralndikasi cabut gigi.asces 16 Nov 2013

3. Dianti S. 2016. Pengertian Tekanan darah dan Mengukur Tekanan darah.

4. Elisa. 2013. Indikasi dan Kontra indikasi Pencabutan gigi. Universitas Gajah Mada

5. Fausiah F, WiduryJ . 2005. Psikologi Abnormal Klinis Dewasa. Jakarta :Universitas Indonesia.. 
6. Hardiani CA. 2012.Kecemasan Dalam Menghadapi Masa Bebas Pada Narapidana Anak Di Lembaga Pemasyarakatan Anak Kutoarjo2012/skripsi. Yogyakarta Universitas Negeri Yogyakarta

7. Janiwarti $B$, Saragih $M$, Pieter $H Z$. 2011.Pengantar Psikopatologi Untuk Keperawatan. Jakarta: Kencana.

8. Johson R, Taylor W. 2004. Praktik Kebidanan. Jakarta : EGC

9. Kandou, Gunawan , Lolong. 2014. Gambaran Tingkat Kecemasan

Pasien Usia Dewasa Pra Tindakan Pencabutan Gigi Dibalai Pengobatan Rumah Sakit Gigi Dan Mulut Manado/ Jurnal

10. Pontoh $\mathrm{BI}$, Pangemanan $\mathrm{DH}$, Mariati NW . 2015. Hubungan tingkat kecemasan dengan perubahan denyut nadi pada pasien ekstraksi gigi di Puskesmas Tuminting Manado/ Jurnal. Manado : Universitas Sam Ratulangi Manado.

11. Permatasari R. 2013. Hubungan kecemasan dental dengan perubahan tekanan darah pada pasien ekstraksi gigi di Rumah Sakit Gigi dan Mulut Pendidikan (RSGMP) Hj.Halima DG.Sikati Makassar.

12. Ridwan R. 2014. Batas normal tekanan darah berdasarkan usia.

13. Rahmania N. 2014. Denyut Nadi Manusia.

14. Rehatta VC. 2014. Gambaran Pencabutan Gigi Anak DiPuskesmas Bahu Manado Jurnal

15. Rynda FR. 2016. Perbedaan Tingkat Kecemasan Anak Usia 6-12 Tahun Sebelum Dan Sesudah Perawatan Pencabutan Gigi Dengan Menggunakan Anestesi Topikal Di Rsgm Unhas/skripsi . Makassar: Universitas Hasanuddin

16. Shalma J. 2013. Exodontia Lengkap

17. Tamunu F, Wantania FE, Mariati NW. 2015. Hubungan scoring dental anxiety scale dengan perubahan tekanan darah pasien ekstraksi gigi di Puskesmas Bahul Jurnal. Manado : Universitas Sam Ratulangi Manado.

18. Pratiwi RP . 2010. Pengertian Kecemasan 